\title{
Automatic change detection in vision: Adaptation, memory mismatch, or both? II: Oddball and adaptation effects on event-related potentials
}

\author{
Flóra Bodnár ${ }^{1,2} \cdot$ Domonkos File ${ }^{1,2,3}$ - István Sulykos ${ }^{1,2,3} \cdot$ Krisztina Kecskés-Kovács $^{1}$ • \\ István Czigler ${ }^{1,2}$
}

Published online: 29 August 2017

(C) The Psychonomic Society, Inc. 2017

\begin{abstract}
In this study we compared the event-related potentials (ERPs) obtained in two different paradigms: a passive visual oddball paradigm and an adaptation paradigm. The aim of the study was to investigate the relation between the effects of activity decrease following an adaptor (stimulusspecific adaptation) and the effects of an infrequent stimulus within sequences of frequent ones. In Experiment 1, participants were presented with different line textures. The frequent (standard) and rare (deviant) texture elements differed in their orientation. In Experiment 2, windmill pattern stimuli were presented in which the number of vanes differentiated the deviant and standard stimuli. In Experiment 1 the ERP differences elicited between the oddball deviant and the standard were similar to the differences between the ERPs to the nonadapted and adapted stimuli in the adaptation paradigm. In both paradigms the differences appeared as a posterior negativity with the latency of $120-140 \mathrm{~ms}$. This finding demonstrates that the representation of a sequential rule (successive presentation of the standard) and the violation of this rule are not necessary for deviancy effects to emerge. In Experiment 2 (windmill pattern), in the oddball paradigm the difference potentials appeared as a long-lasting negativity. In the adaptation
\end{abstract}

Domonkos File

file.domonkos@ttk.mta.hu

1 Institute of Cognitive Neuroscience and Psychology, Centre for Natural Sciences, HAS, P.O. Box 286, Budapest 1519, Hungary

2 Institute of Psychology, Eötvös Loránd University, Budapest, Hungary

3 Doctoral School of Psychology, Eötvös Loránd University, Budapest, Hungary condition, the later part of this negativity (after $200 \mathrm{~ms}$ ) was absent. We identified the later part of the oddball difference potential as the genuine visual mismatch negativity - that is, an ERP correlate of sequence violations. The latencies of the difference potentials (deviant minus standard) and the endogenous components (P1 and N1) diverged; therefore, the adaptation of these particular ERP components cannot explain the deviancy effect. Accordingly, the sources contributing to the standard-versus-deviant modulations differed from those related to visual adaptation; that is, they generated distinct ERP components.

Keywords Visual mismatch negativity - Adaptation · Change detection $\cdot$ Sequential regularity $\cdot$ Sensory memory

\section{Visual mismatch negativity to various stimuli}

Within sequences of homogeneous visual events, a violation of the sequence regularity (a deviant) elicits an electrical response in the brain that differs from those elicited by the frequent (standard) stimuli. This difference is present even when the deviants are unrelated to the task requirements (e.g., a task demanding focal attention). Differences in the event-related potentials (ERPs) in response to deviant and standard stimuli usually emerge in the form of a posterior negativity and are usually termed the visual mismatch negativity (vMMN; for reviews, see Czigler, 2007; Kimura et al., 2011; Stefanics, Kremláček, \& Czigler, 2014). The vMMN occurs in response to deviant stimulus features (orientation: e.g., Astikainen, Lillstrang, \& Ruusuvirta, 2008; Jack, Roeber, \& O'Shea, 2015; Kimura, Katayama, Ohira, \& Schröger, 2009; Kimura \& Takeda, 2013; Sulykos \& Czigler, 2011; Takács, Sulykos. Czigler, Barkaszi, \& Balázs, 2013; spatial frequency: e.g., Kenemans, Hebly, van den Heuvel, \& Grent-'T-Jong, 2010; Sulykos \& 
Czigler, 2011; Susac, Heslenfeld, Huonker, \& Supek, 2014; color: e.g., Czigler, Balazs, \& Winkler, 2002; Liu \& Shi, 2008; Müller et al., 2012; Sysoeva, Lange, Sorokin, \& Campbell, 2014; motion direction: e.g., Kremláček et al., 2006; Pazo-Alvarez, Amenedo, \& Cadaveira, 2004) or categories (symmetry: Kecskés-Kovács, Sulykos, \& Czigler, 2013b; color: Athanasopoulos, Dering, Wiggett, Kuipers, \& Thierry, 2010; Clifford, Holmes, Davies, \& Franklin, 2008; Mo, Xu, Kay, \& Tan, 2011; facial emotion: e.g., Astikainen \& Hietanen, 2009; Huang, Zhou, \& Hu, 2013; Kreegipuu et al., 2013; Stefanics, Csukly, Komlosi, Czobor, \& Czigler, 2012; Zhao \& Jing, 2006; face gender: Kecskés-Kovács, Sulykos, \& Czigler, 2013a; for reviews, see Czigler, 2007; Kimura et al., 2011; Kremláček et al., 2016; Stefanics et al., 2014).

\section{Stimulus-specific adaptation and the "genuine mismatch negativity"}

ERP differences between deviant and standard stimuli can be attributed to two processes. First, repetition of events decreases the elicited activity to these stimuli (for a comprehensive discussion, see May \& Tiitinen, 2010). Accordingly, frequency difference between the presentation of deviant and standard stimuli are a putative source of these activity differences. Second, regular presentation of equivalent events forms memory representations of the sequential rule. Representations of incoming stimuli are compared to the representations of regular events. A mismatch between the stimuli violating the sequential rule and the regular stimuli elicits an additional ERP component. The equal-probability control paradigm (Jacobsen \& Schröger, 2001; Schröger \& Wolff, 1996) is the most common method of separating the two sources of deviant-related activity. An equal-probability sequence consists of stimuli with variable parameters. The probability of each parameter is equal to the probability of the oddball deviant. In this type of sequence, the stimuli are presented in a random order (no sequential regularity). Differences between the ERPs elicited by the oddball deviant and those elicited by the physically identical stimuli from the control sequence are considered to be the consequence of sequential regularity violations (present in the oddball sequence, but absent in the control sequence; called the "genuine mismatch negativity": genunine $v M M N$ ). As Kimura (2012) formulated it, the genuine vMMN is a temporally based ERP component (it should be noted that in the mismatch negativity literature, the more frequently used term is "refractoriness"; for an attempt to clarify the terminology, see O'Shea, 2015). In other fields of cognitive neuroscience, changes in repetition-related activity are considered to be functionally significant phenomena (see, e.g., O'Shea, 2015, for a short discussion). Stimulus-specific adaptation (SSA) is regarded as being a consequence of memory acquisition or recalibration. SSA can be observed at almost all levels of the visual system (for reviews, see Kohn, 2007; Webster, 2011), though the SSA characteristics differ across levels. The SSA effects (or repetition suppression) ${ }^{1}$ measured with ERP and brain imaging (fMRI) are frequently used to investigate memory-related phenomena. In these studies, adaptor and test stimuli are presented one after another, and presentation of the adaptor decrease responses to the test stimuli. Adaptation effects have been present for both low-level stimulus features (e.g., tilt aftereffect, Kanai, Tsuchiya, \& Verstraten, 2006; or motion and orientation, Larsson \& Harrison, 2015) and complex stimulus characteristics (e.g., gender of faces, Kovács, Cziraki, Vidnyánszky, Schweinberger, \& Greenlee, 2008; or memory for visual scenes, Park, Intraub, Yi, Widders, \& Chun, 2007).

\section{Comparison of event-related potentials in an oddball and in an adaptation paradigm}

The aim of the present study was to compare the effects of deviant stimuli in oddball paradigms to the effects of nonadapted (or less-adapted) stimuli (hereafter, deviant) in the adaptation paradigm. This comparison is essential in study of the mismatch negativity, because it provides a direct insight into the relationship between the results of visual adaptation and vMMN studies. Theories of the mismatch negativity propose a comparison between representations of the input and existing memories, such as in the memory trace theory (for a review, see Näätänen, Paavilainen, Rinne, \& Alho, 2007) and predictive-coding processes (for a review, see Garrido, Kilner, Stephan, Klaas, \& Friston, 2008). According to these theories, at least part of the deviant-related activity is considered to be the consequence or the output of a comparison stage ("genuine mismatch negativity"). On the other hand, SSA does not require a separate comparison stage (May \& Tiitinen, 2010). In a direct comparison of the oddball and adaptation paradigms, the SSA and genuine mismatch signals can be separated.

\section{The two stimulus types of the present study: Line textures and windmill patterns}

For this study we selected two different stimulus types. The first type was a texture of oblique lines, and the deviance was the change of line orientation. Orientation deviance, the change in an elementary visual feature, has frequently been assessed in previous studies. Some studies have employed the equal-probability control method (Jacobsen \& Schröger, 2001; Schröger \& Wolff, 1998), using oblique lines in an

\footnotetext{
${ }^{1}$ It should be noted that the terms "refractoriness," "stimulus-specific adaptation," "repetition suppression," and "habituation" sometimes refer to the same phenomenon.
} 
attempt to separate adaptation from comparison-related effects (Astikainen et al., 2008; File, Bodnár, Sulykos, KecskésKovács, \& Czigler, 2017; Kimura et al., 2009; Kimura \& Takeda, 2013). However, the stimulus patterns in these studies have differed. Astikainen et al. (2008) presented single lines; Kimura et al. (2009), Kimura and Takeda (2013), and Takács et al. (2013) presented lines surrounded by task-related stimuli; and Sulykos and Czigler (2011) presented a line texture in the hemifield opposite the location of the task-related events. Though each study investigated "orientation deviancy," the various stimulus arrangements produced different results. For example, the latency ranges of the responses reported by Kimura et al. (2009) and Kimura and Takeda (2013) were much longer than those reported by Sulykos and Czigler (2011). In the present study, we chose line texture stimuli. Differences between the deviant and standard orientations using these stimuli emerged as a single negativity with its peak latency in the 130- to 140 -ms range.

The second type of stimuli was the windmill pattern. These patterned stimuli were first used by Maekawa et al. (2005; Maekawa et al., 2013; Maekawa, Tobimatsu, Ogata, Onitsuka, \& Kanba, 2009) to study the vMMN. Windmill patterns elicited deviant-related posterior negativities in two latency periods ( $\sim 140-230$ and $\sim 230-320 \mathrm{~ms}$ ). Our aim was to investigate whether the early and late deviance-related negativities were similar in the oddball and adaptation conditions. In other words, as Kimura et al. (2009) suggested, only the later part of the negative difference potential is the genuine vMMN.

\section{General outline of the studies and expected results}

In both experiments we introduced a traditional passive oddball paradigm. In the adaptation paradigm the adaptors preceded the test stimuli, and the adaptor and test stimuli had either identical or different visual characteristics. In Experiment 1 the adaptor duration either corresponded to the sum of the average duration of the oddball standards between two deviants (squeezed adaptation sequences) or was identical to the average duration of the whole period between two oddball deviants (i.e., the stimulus duration plus the interstimulus interval; filled adaptation sequences). Because of the longer adaptor duration, we expected larger adaptation effects in the filled adaptation sequences. In Experiment 2, only the latter condition (larger expected adaptation effect) was introduced. As the main issue of the study, we compared the deviance-related ERP effects of the oddball condition to the ERP difference to stimuli preceded by different and identical adaptors. We expected that adaptation would influence the earlier part of the difference potential, whereas in the later part we expected to find genuine mismatch effects. It is important to emphasize that the oddball deviants violated a sequential rule; in other words, these stimuli were nonpredicted. The adaptation tasks included conditions in which the test stimuli were identical to the adaptors (but had shorter durations), as well as conditions in which the test and adaptor stimuli were different. Accordingly, in both conditions of the adaptation tasks the test stimuli did not violate a sequential rule. Therefore the possible ERP difference between the two experiments can be regarded as a difference between nonpredictability and the lack of nonpredictability. It is important to note that regular stimulus presentation does not mean the automatic registration of the regularity at the level of automatic visual processing. This is because the sensitivity of the memory system underlying the vMMN is limited in the time domain. Kimura, Widmann, and Schröger (2010) compared ERPs to the last stimuli of regular AAAAB cycles to the ERPs to random deviants of oddball sequences. They obtained similar vMMNs in both sequences. The duration of the cycles was $3,750 \mathrm{~ms}$ - that is, a duration at which the system did not register the regularity. It is well established that eliciting the vMMN requires at least four preceding standards and the deviant following the standards (e.g., Maekawa et al., 2009). In our study, even in the condition with shorter interstimulus intervals, the length of five cycles was in the range of 3,000$4,000 \mathrm{~ms}$, and was much longer in the adaptation condition, with longer cycles. Therefore, it is improbable that the automatic memory system was capable of predicting the characteristics of the following stimulus.

It is important to emphasize that in both experiments in both paradigms, the ERP-related stimuli were task-irrelevant. Furthermore, we made attempts to introduce tasks requiring permanent attention and fixation - that is, to ensure that the ERP-related stimuli were unattended (Czigler, 2007). In this way we avoided the involvement of attention-related negativities (e.g., Czigler \& Csibra, 1992; Hillyard \& Münte, 1984; Wijers, Mulder, Okita, \& Mulder, 1989) in the ERPs.

\section{Experiment 1}

\section{Method}

Participants Seventeen paid students (ten female, seven male; mean age $=21.8$ years, $S D=2.03$ ) with normal or corrected-to-normal vision participated in the study. Written consent was obtained from all participants prior to the experimental procedure. The study was conducted in accordance with the Declaration of Helsinki and approved by the Committee of Ethics of the Psychology Institutes in Hungary.

Stimuli The ERP-related stimuli were presented in the lower two thirds of the screen (17-in. LCD monitor with a $60-\mathrm{Hz}$ refresh rate). The stimuli consisted of a $6 \times 4$ matrix of gray oblique lines (Fig. 1). The line orientations were either $45^{\circ}$ or $135^{\circ}$. The luminance of the lines was $36.7 \mathrm{~cd} / \mathrm{m}^{2}$, and the 


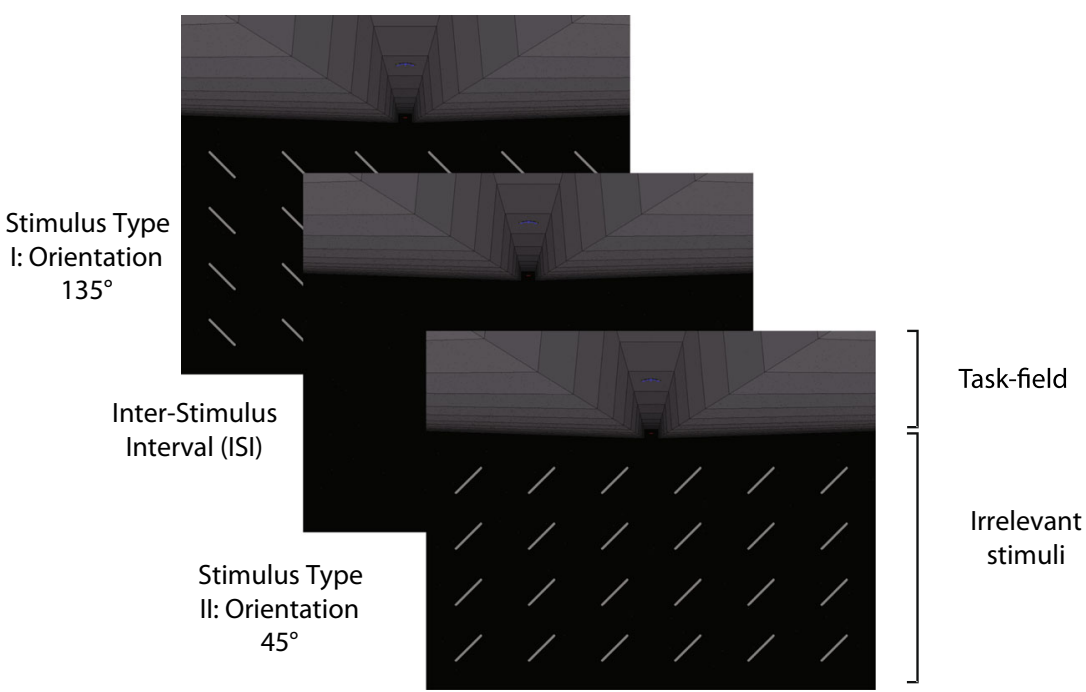

Fig. 1 Experiment 1: Experimental stimuli and a sample of the stimulus display

luminance of the dark background was $0.5 \mathrm{~cd} / \mathrm{m}^{2}$. The length of the lines was $1.3^{\circ}$, and their width was $0.1^{\circ}$ (from a $120-\mathrm{cm}$ viewing distance). The distance between the line segments within a row was $2.62^{\circ}$, and the distance between the rows was $2^{\circ}$.

The task-related events were displayed continuously. The task was a simple video game. The participants had to control a blue spaceship flying through a canyon by using a gamepad. Every second, an "alien" spaceship appeared in the canyon and moved toward the participant's spaceship. The color of the "alien" spaceship was either green $(p=.4)$ or red $(p=.6)$. The aim of the task was to catch the green spaceships and to avoid the red ones. The task demanded continuous fixation of the location from which the spaceships appeared. The "alien" spaceships never appeared simultaneously with the ERPrelated stimuli. Figure 1 shows a sample of the stimulus display. For more details, see Sulykos and Czigler (2011). However, we modified the task described by Sulykos and Czigler to make it more demanding, by increasing the speed of the spaceship. This modification increased the attentional demands of the task and required more stable fixations. ${ }^{2}$ To assess performance, the average hit rate and the average rate of successful avoidance were measured.

Procedure The task consisted of three conditions: oddball, filled adaptation, and squeezed adaptation. In the oddball condition, the stimulus (line textures) duration was $100 \mathrm{~ms}$ and the stimulus onset asymmetry (SOA) was $500 \mathrm{~ms}$. In this condition $83 \%$ of the stimuli were standard and $17 \%$ were deviant. A reverse control procedure was introduced-that

\footnotetext{
${ }^{2}$ Stimulation of identical locations is essential if neural structures with small receptive fields (e.g., V1) are being investigated. However, the source of the vMMN is beyond the striate cortex (see, e.g., Kimura, Kondo, Ohira, \& Schröger, 2012; Kimura, Ohira, \& Schröger, 2010; Müller et al., 2012; Susac et al., 2014).
}

is, both texture orientations $\left(45^{\circ}\right.$ and $\left.135^{\circ}\right)$ were presented as the standard and as the deviant. In both of the standarddeviant arrangements, 800 stimuli were presented (136 deviant). This procedure allowed us to compare stimuli with identical physical characteristics. To compare the oddball and adaptation conditions, we also presented homogeneous sequences - that is, series without deviant stimuli ("standard only"). In the filled adaptation condition, long and short stimuli were presented. The long stimuli served as the adaptors, and the short stimuli served as the test. The average length of the adaptors was equal to the sum of the duration of the oddball standards between the two deviants, plus the interval between the stimuli $(1,100-3,100 \mathrm{~ms}$, mean $=2,100 \mathrm{~ms})$. During the filled adaptation condition, two types of sequences were presented. In the homogeneous sequences the orientations of the test and long stimuli were identical; in the heterogeneous sequences, the orientation of the test stimulus differed (deviant). The filled condition consisted of 274 stimuli (137 test stimuli). During the squeezed adaptation sequences, the average duration of the long stimuli was identical to the sum of the durations of the oddball standards between the two deviants $(400-700 \mathrm{~ms}$, mean $=550 \mathrm{~ms})$. Like the filled condition, the squeezed condition consisted of both homogeneous and heterogeneous sequences. The squeezed condition consisted of 289 stimuli (144 test stimuli). As in the oddball condition, we applied the reverse control procedure in the two adaptation conditions. In both adaptation conditions the interval between the adaptor offset and the test onset was $400 \mathrm{~ms}$.

There were 12 sequences within each session: two oddball sequences, two homogeneous sequences with short standard stimuli only, and four squeezed and four filled sequences. Because of the longer durations of the sequences, the oddball and filled conditions were divided into two blocks. Therefore, we presented 20 blocks within a session: four oddball blocks, four blocks with "standard only," two heterogeneous 
squeezed blocks, two homogeneous squeezed blocks, four heterogeneous filled blocks, and four homogeneous filled blocks. The average block duration was $3.3 \mathrm{~min}$, the $\sim 30$-s breaks were interposed between the blocks. The block order was counterbalanced across participants.

The adaptation effect was defined as the difference between the ERPs in response to the test stimuli in the heterogeneous and homogeneous sequences. The vMMN was defined as the difference between the response to the deviant stimuli in the heterogeneous sequences and the standard in the homogeneous sequences. In summary, there were three conditions: oddball, filled adaptation, and squeezed adaptation. In each condition the reverse control procedure was introduced. Figure 2 shows the outline of the experimental design.

Measurement of electrical brain activity Electrical brain activity was recorded from 61 locations $(\mathrm{Ag} / \mathrm{AgCl}$ electrodes; EasyCap, Synamps2 amplifier, NeuroScan recording system) according to the extended 10-20 system (DC $70 \mathrm{~Hz}, 500-\mathrm{Hz}$ sampling rate). The reference electrode was placed on the tip of the nose, and the ground electrode was placed on the forehead. A horizontal electrooculogram (EOG) was recorded using a bipolar configuration between electrodes positioned laterally to the outer canthi of the two eyes. Vertical eye movements were monitored using a bipolar montage between electrodes placed above and below the right eye. The electroencephalogram (EEG) and EOG signals were digitally low-pass filtered at $30 \mathrm{~Hz}$ with a finite impulse response (FIR) filter (filter order $=184$, Kaiser Beta $=5.6533$ ) and high-pass filtered at $0.1 \mathrm{~Hz}$ with a FIR filter (filter order $=9,056$, Kaiser Beta $=5.6533$ ). Epochs ranging from -100 to $400 \mathrm{~ms}$ relative to the onset of the test stimulus were selected from the adaptation trials. Equivalent epochs aligned on the deviant and standard stimuli were selected from the oddball condition. We selected trials from the homogeneous blocks with short stimuli presented at the same position as the deviants in the oddball blocks. We calculated the averages of these ERPs. The mean voltage during the 100 -ms prestimulus interval served as the baseline for the amplitude measurements. Epochs with an amplitude change exceeding $\pm 100 \mu \mathrm{V}$ on any channel were rejected from further analysis. To increase the number of averaged stimuli, we collapsed across ERPs in response to the corresponding events of the reversed sequences.

Deviance-related activity was determined in three steps. In the first step, we tested whether the difference between the deviant and standard potentials differed from zero in any of the channels for at least ten sample points within a 20-ms bin centered on the peak of the difference potential (using $t$ tests). In the second step, only the differences that met this criterion were considered. We constructed two regions of interest (ROIs): one parieto-occipital ROI comprising the PO3, $\mathrm{POz}$, and $\mathrm{PO} 4$ locations, and an occipital ROI comprising the $\mathrm{O} 1$, $\mathrm{Oz}$, and $\mathrm{O} 2$ locations. The mean of the differences within a 20$\mathrm{ms}$ time window centered on the largest negative value within each ROI was then compared to zero using a $t$ test (separately for the oddball, filled, and squeezed conditions). In the third step, the negativities with significant differences were compared using two-way analyses of variance (ANOVAs) with Condition and ROI as factors. Individual peak latency values were measured and compared within the same range.

To investigate the effects of different onset-to-onset durations of the stimuli in the three conditions, we compared the N1 of the deviant-related ERPs using a two-way ANOVA with Condition and ROI as factors. To test the relationship between
ODDBALL
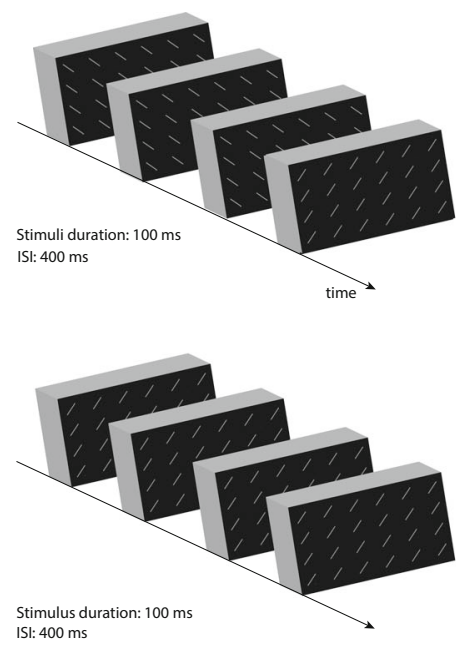

HOMOGENEOUS CONTROL
SQUEEZED ADAPTATION
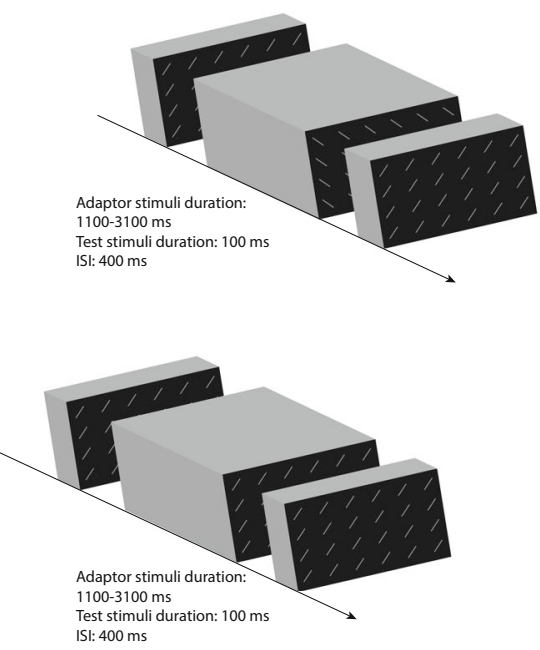

HOMOGENEOUS CONTROL
FILLED ADAPTATION
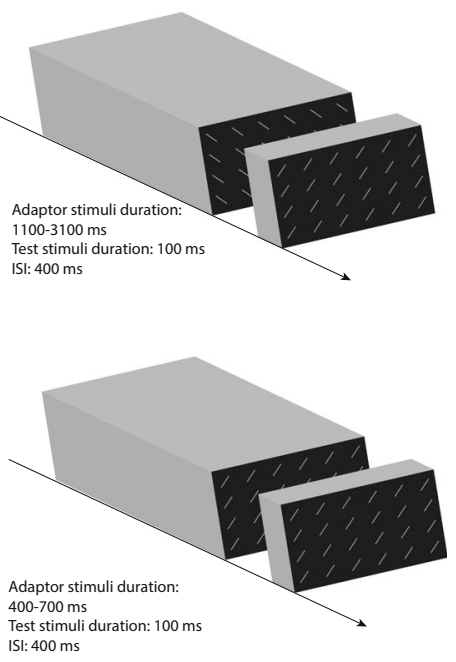

HOMOGENEOUS CONTROL

Fig. 2 Experiment 1: Outline of the stimulus sequences during the oddball, squeezed, and filled conditions 
the N1 and the difference potential, the latencies of these components were compared using a three-way ANOVA with Component (difference potential or N1), Condition, and ROI as factors. Latency differences between the $\mathrm{N} 1$ and the difference potential would suggest that the sources of these two components were distinct from one another. When appropriate, the Greenhouse-Geisser correction procedure was applied. Post-hoc analyses were carried out using Tukey's HSD test. Reported descriptions of the interactions were supported by the post-hoc test. Only results that exhibited effects of stimulus and condition (main effects and interactions) will be reported. Behavioral performance was assessed in terms of hit and avoidance rates.

\section{Results}

Behavioral results The hit rates during the oddball, squeezed, and filled conditions were $64.2 \%, 62.5 \%$, and $64.2 \%$, respectively. The correct avoidance rates were $75.1 \%, 72.0 \%$, and $74.1 \%$, respectively. The hit rates did not differ across conditions; however, we did find a significant effect of condition on the avoidance rate $\left[F(2,32)=5.34, p<.05, \varepsilon=.86, \eta_{\mathrm{p}}{ }^{2}=.25\right]$. According to Tukey's HSD tests, performance was lower on the squeezed than on the filled trials.

Event-related potentials As Fig. 3 shows, the ERPs over the posterior locations consisted of three components: the P1 (80$100 \mathrm{~ms}), \mathrm{N} 1(100-200 \mathrm{~ms})$, and P2 (200-400 ms). This component structure was similar in all conditions. The deviantminus-standard difference (difference between the ERPs in response to the test stimuli in the heterogeneous and homogeneous sequences during the adaptation conditions, and the difference between the ERPs in response to the deviant and the corresponding stimuli in the homogeneous sequence during the oddball condition) emerged in the $100-$ to $150-\mathrm{ms}$ period. In all conditions the difference potentials had posterior maxima. Table 1 details the latencies and amplitudes of the exogenous components (P1, N1, P2) at the two ROIs.

Difference potentials Difference potentials were measured during the 112- to 132-ms time window on adaptation trials and during the 114- to 134-ms time window on the oddball trials - that is, the 20-ms window centered on the largest negativity within the range of significant $t$ tests (at least ten consecutive values at any location).

Table 2 shows the peak amplitudes and latencies of the difference potentials at the two ROIs. The latencies did not differ across the three conditions. For the negativity amplitudes, the values differed significantly from zero in all conditions and in both ROIs $[t(16)=4.16-6.65$, Bonferronicorrected $p<.001]$. Because the negativity appeared in all conditions, we conducted a two-way ANOVA with Condition and ROI as factors. The main effect of condition $\left[F(2,32)=3.86, p<.05, \varepsilon=.95, \eta_{\mathrm{p}}{ }^{2}=.19\right]$ and the Condition $\times$ ROI interaction $\left[F(2,32)=5.9, p<.05, \varepsilon=.93, \eta_{\mathrm{p}}{ }^{2}=.26\right]$ were significant. The negativity was smaller in the squeezed condition. Furthermore, on oddball trials the negativity was larger in the parieto-occipital than in the occipital ROI. Figure 4 shows the difference potentials and their surface distributions.

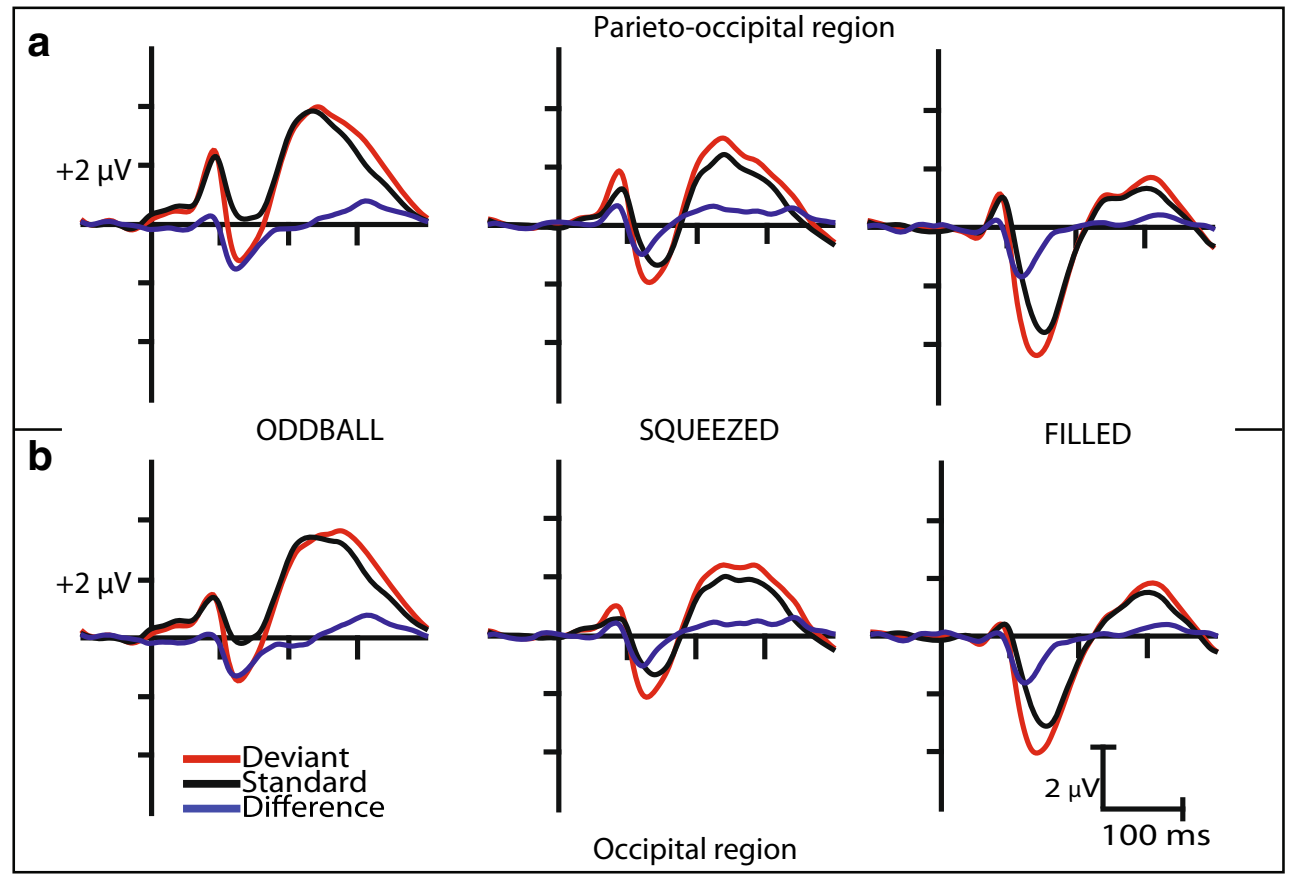

Fig. 3 Experiment 1: Event-related potentials and difference potentials in the three conditions (oddball, squeezed, and filled) from the parieto-occipital and occipital regions of interest 
Table 1 Experiment 1: Grand averages of the epoch mean amplitudes and peak latencies of the exogenous components (P1, N1, P2) measured at the parieto-occipital and occipital regions

\begin{tabular}{llllllll}
\hline & & & & & P1 & \\
\hline Region & Stimulus & Amplitude $(\mu \mathrm{V})$ & Latency $(\mathrm{ms})$ & Amplitude $(\mu \mathrm{V})$ & Latency $(\mathrm{ms})$ & Amplitude $(\mu \mathrm{V})$ & Latency $(\mathrm{ms})$ \\
Parieto-occipital & Oddball deviant & $2.27 \pm 0.3$ & $90.94 \pm 2.48$ & $-1.13 \pm 0.45$ & $134.82 \pm 3.96$ & $3.97 \pm 0.51$ & $252.35 \pm 6.89$ \\
& Oddball standard & $2.12 \pm 0.37$ & $94.12 \pm 3.64$ & $0.27 \pm 0.43$ & $138.47 \pm 6.58$ & $3.84 \pm 0.46$ & $239.76 \pm 5.18$ \\
& Squeezed deviant & $1.65 \pm 0.3$ & $88.35 \pm 3.04$ & $-1.84 \pm 0.57$ & $137.06 \pm 4.46$ & $2.93 \pm 0.51$ & $250 \pm 8.04$ \\
& Squeezed standard & $1.11 \pm 0.33$ & $88.47 \pm 4.13$ & $-1.27 \pm 0.53$ & $139.88 \pm 4.79$ & $2.36 \pm 0.41$ & $255.18 \pm 7.66$ \\
& Filled deviant & $0.88 \pm 0.3$ & $87.06 \pm 2.79$ & $-4.31 \pm 0.65$ & $145.18 \pm 3.39$ & $1.67 \pm 0.3$ & $301.06 \pm 6.61$ \\
& Filled standard & $0.83 \pm 0.29$ & $92.71 \pm 2.92$ & $-3.51 \pm 0.53$ & $151.76 \pm 2.84$ & $1.31 \pm 0.28$ & $291.65 \pm 6.95$ \\
Occipital & Oddball deviant & $1.31 \pm 0.28$ & $86.82 \pm 3.95$ & $-1.37 \pm 0.49$ & $130.71 \pm 4.54$ & $3.47 \pm 0.4$ & $264.82 \pm 6.86$ \\
& Oddball standard & $1.22 \pm 0.29$ & $91.29 \pm 5.82$ & $-0.14 \pm 0.44$ & $127.18 \pm 7.59$ & $3.43 \pm 0.4$ & $244.71 \pm 4.92$ \\
& Squeezed deviant & $0.86 \pm 0.31$ & $84.94 \pm 3.94$ & $-2.02 \pm 0.57$ & $136.35 \pm 4.79$ & $2.42 \pm 0.39$ & $264.24 \pm 8.1$ \\
& Squeezed standard & $0.49 \pm 0.31$ & $90.35 \pm 6.88$ & $-1.28 \pm 0.51$ & $139.88 \pm 5.02$ & $2.02 \pm 0.32$ & $259.18 \pm 7.57$ \\
& Filled deviant & $0.2 \pm 0.31$ & $80.12 \pm 5.29$ & $-3.99 \pm 0.62$ & $142.24 \pm 3.86$ & $1.82 \pm 0.23$ & $299.88 \pm 4.86$ \\
& Filled standard & $0.27 \pm 0.27$ & $90 \pm 4.51$ & $-3.06 \pm 0.48$ & $151.76 \pm 2.84$ & $1.5 \pm 0.25$ & $292.59 \pm 6.3$ \\
\hline
\end{tabular}

Values represent the means \pm standard errors.

The effect of onset-to-onset time on the N1 and the emergence of a long-lasting ERP effect Irrespective of the deviancy effects, the ERPs in the three conditions were markedly different (see Fig. 5 for ERPs solely from the homogeneous conditions). Because of the overlap in the negative difference potentials, and to avoid effects contributed by the preceding stimuli with the identical orientation (SSA), we compared the latencies and amplitudes of the N1 components from heterogeneous sequences. Table 1 shows the N1 latencies and amplitudes at the two ROIs. The N1 latency was longest on filled trials and shortest on oddball trials $[F(2,32)=5.5, p<.01, \varepsilon=$ $\left..76, \eta_{\mathrm{p}}{ }^{2}=.26\right]$. Likewise, the $\mathrm{N} 1$ amplitude was largest on filled trials and smallest on oddball trials $[F(2,32)=61.77$, $\left.p<.0001, \varepsilon=.87, \eta_{\mathrm{p}}{ }^{2}=.79\right]$.

N1 and deviancy N1 latencies and the latencies of the difference potentials were compared using a two-way ANOVA with Component (N1, difference potential) and ROI as factors. Only deviant-related N1 latencies were involved in the analysis. The main effect of component was significant $[F(1,16)=$
29.36, $\left.p<.0001, \varepsilon=.70 \eta_{\mathrm{p}}{ }^{2}=.64\right]$ : The deviant-related negativity had a shorter latency than the N1 component (124 vs. $138 \mathrm{~ms}$ ).

\section{Discussion}

An important result of the present study was the significant difference between the ERPs in response to the test stimuli of the heterogeneous and homogeneous sequences in all conditions. In all conditions the deviant-minus-standard difference (i.e., textures with different orientations from the standard or adaptor) elicited posterior negativities within the 100- to 140 ms range. The magnitude of the negativity was slightly smaller in the squeezed condition, and the behavioral performance during this condition was slightly lower. It is possible that the long duration of the filled stimuli relative to the squeezed stimuli decreased the former's saliency. These saliency differences impacted both the behavioral performance (lower avoidance rate in the squeezed condition) and the ERPs. Similar posterior negativities in the oddball, filled, and squeezed conditions are
Table 2 Experiment 1: Grand averages of epoch mean amplitudes and peak latencies of the difference waves measured at parieto-occipital and occipital regions

\begin{tabular}{llll}
\hline & & $112-132 \mathrm{~ms}$ & \\
\hline Region & Stimulus & Amplitude $(\mu \mathrm{V})$ & Latency (ms) \\
Parieto-occipital & Oddball difference & $-1.44 \pm 0.23^{* *}$ & $124.94 \pm 2.07$ \\
& Squeezed adaptation difference & $-0.91 \pm 0.19^{* *}$ & $124.94 \pm 2.98$ \\
& Filled adaptation difference & $-1.6 \pm 0.24^{* *}$ & $123.53 \pm 1.91$ \\
Occipital & Oddball difference & $-1.25 \pm 0.24^{* *}$ & $125.29 \pm 2.53$ \\
& Squeezed adaptation difference & $-0.95 \pm 0.22^{* *}$ & $124.12 \pm 3.67$ \\
& Filled adaptation difference & $-1.56 \pm 0.25^{* *}$ & $122.82 \pm 5.17$ \\
\hline
\end{tabular}

Values represent the means \pm standard errors. ${ }^{* *} p<.01$ 


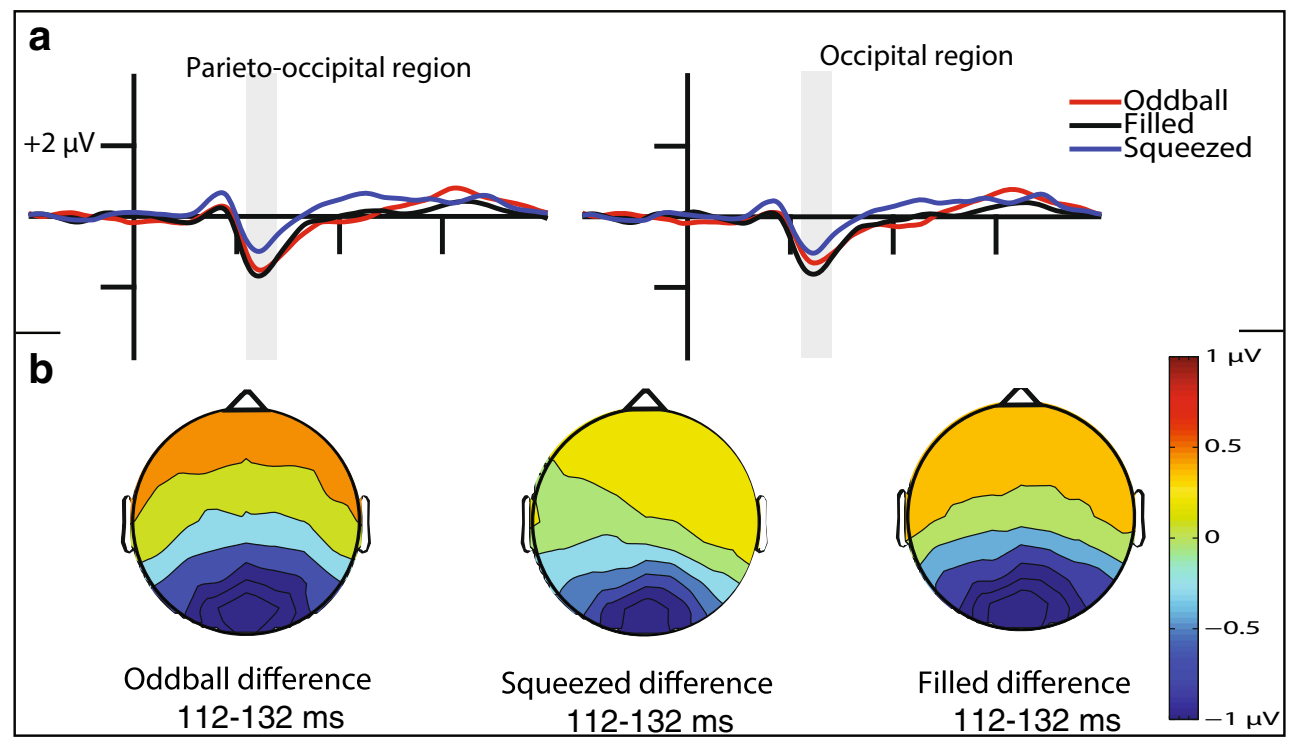

Fig. 4 Experiment 1: Difference potentials from the three (oddball, squeezed, and filled) conditions, as well as their surface distributions

inconsistent with the traditional theoretical view on the deviance-related effect of the oddball paradigm. This is because mismatch components are considered to index violations of sequential regularities (e.g., Kimura, 2012; Stefanics, Kimura, \& Czigler, 2011; Winkler \& Czigler, 2012). However, in the adaptation paradigm the deviants did not violate the sequential rules; test stimuli were preceded by a single event (adaptor). Unfortunately, we are not aware of any studies that have evaluated this issue in the auditory modality. One reasonable explanation (at least in the visual modality) is that long-lasting stimuli form a representation in memory; therefore, ERPs in response to a stimulus with similar characteristics (orientation in the present study) are susceptible to SSA. It is important to note that this possibility does not exclude representations of sequential regularities or effects of sequential regularity violations for different types of stimuli in the ERP.

In addition to the memory mismatch interpretation of the deviant-related negativity (e.g., Näätänen, Jacobsen, \& Winkler, 2005), an alternative interpretation could be that the ERP differences between the standard and deviant events resulted from decreased activity in response to the standardthat is, ERP refractoriness or ERP adaptation (e.g., May \& Tiitinen, 2010). Our results are consistent with this explanation. Studies investigating orientation deviancy using the equal-probability control may help clarify the memory mismatch versus adaptation issue. Astikainen et al. (2008) assessed deviant-minus-control differences in the 185- to 205 -ms range, but only at short ISIs (400 ms). The scalp distribution of the genuine vMMN was smaller than the deviantminus-standard difference. In this study single bars were presented. In an experiment by Kimura et al. (2009), the stimuli were also single bars. In their study the equal-probability control abolished the early difference potential (in the 100-to 150ms range), whereas in the 150 - to 350 -ms range these authors obtained a genuine vMMN. It should be noted that attention was not controlled well in these studies. One might suppose that the auditory task in the Astikainen et al. (2009) study did not prevent attentional capture by the bars at the center of the visual field. The participants in the Kimura et al. (2009) study discriminated between the terminal shapes of the bars, whereas the bar orientation was irrelevant. However, as results in object-related attention studies have shown (e.g., Duncan, 1984), in the case of attended objects (presented on an otherwise empty field), attentional processing extends to the other features. Finally, in a study conducted by Kimura and Takeda (2013), the target stimuli were surrounded by bars - that is, the

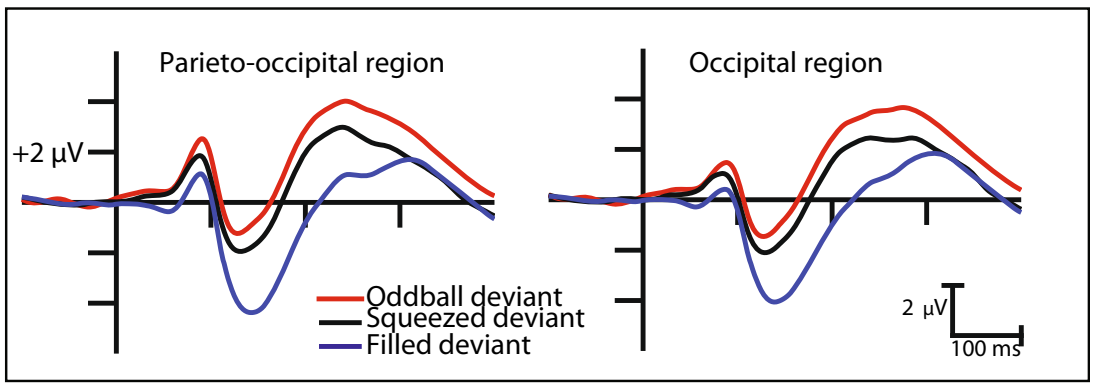

Fig. 5 Experiment 1: Event-related potentials from homogeneous sequences of the oddball, squeezed, and filled adaptation conditions 
bars made up a frame. In this study the genuine vMMN emerged in the 150 - to $300-\mathrm{ms}$ time period, and the scalp distribution of this negativity (right side dominant) differed from the distribution of the deviant-minus-standard difference. To anticipate the findings of a companion study, we included the equal-probability control in a paradigm similar to that of the present study (File et al., 2017), and the control procedure abolished the deviance effect completely. Although neither of the studies above obtained a genuine vMMN in the early (100$140 \mathrm{~ms}$ ) epoch, adaptation seems to be a plausible explanation of the present results.

The amplitude and the latency of the N1 in response to the deviants was larger in the filled than in the other conditions. The longer onset-to-onset duration of this condition might explain these differences. It should be noted that in contrast to findings in the auditory modality (e.g., Pereira et al., 2014), data on stimulus duration effects in the visual modality are rather sparse. Lehtonen (1973) obtained marked interstimulus interval (ISI) effects measured at vertex locations. Comparing 400- and 600-ms ISIs, Neville, Schmidt, and Kutas (1983) demonstrated that the N1 amplitude decreased at longer ISIs. In their oddball study, Astikainen et al. (2008) applied shorter (400-ms) and longer (1,100-ms) ISIs. Unfortunately, the posterior N1 was not observed in their study; however, neither the posterior positivity nor the anterior negativity differed across the two ISI conditions. It seems that the effect of ISI on the N1 component requires further study. Wastell and Kleinman (1980) reported less robust ISI effects at the occipital location than at a more anterior site. In a recent article, Andrade, Butler, Mercier, Molholm, and Foxe (2015) compared ERPs in response to parafoveal checkerboards to those in response to stimulus pairs with varied intrapair intervals, using a paradigm in which the ISI varied across blocks. Considerable interstimulus effects were reported in the blocked paradigm, and the amplitude of the negativity increased during the $130-$ to $180-\mathrm{ms}$ time period. Similar to our results, the N1 increased and the P2 apparently decreased at longer ISIs. It is important to note that long-minus-short ISI differences were present within a wide neural network, far beyond the locations of lower levels of visual structure.

In summary, in the present study we observed enlarged negativities in response to deviant stimuli in the 100- to 140$\mathrm{ms}$ range. These negativities were fairly similar in the oddball and adaptation conditions. As May and Tiitinen (2010) suggested, the emergence of this negativity can be explained by SSA (however, in the General Discussion we put forth an alternative explanation). We also observed a long-lasting posterior negative shift that emerged as a function of the onset-toonset duration.

Our study provided only a weak indication that the deviancy effect was not solely due to amplitude modulations of the N1 peak. The latency of the negative difference potential was shorter than the N1 latency. However, we have to note that the posterior negativity in the $\mathrm{N} 1$ range is an aggregate of various underlying processes (Di Russo, Martínez, Sereno, Pitzalis, \& Hillyard, 2002). Such latency changes can be the consequence of different SSA effects on latent components (Luck, 2005).v

\section{Experiment 2}

In contrast to the studies conducted by Maekawa and colleagues (e.g., 2009), we introduced a more stringent control of attention by requiring participants to perform a continuous tracking task. This task was not particularly demanding, but proper performance required sustained fixation and attention to the task field.

\section{Method}

Participants Nineteen paid students (11 male, eight female; mean age $=23.6$ years, $S D=4.33$ ) participated in the study. Written consent was obtained from all participants prior to the experimental procedure. The study was conducted in accordance with the Declaration of Helsinki and was approved by the Committee of Ethics of the Psychology Institutes in Hungary.

Stimuli and procedure Task-related stimuli appeared at the center of the screen. During the tracking task, participants had to keep a ball within a blue circle $\left(1.8^{\circ}\right.$ in diameter from a 120 $\mathrm{cm}$ viewing distance). The ball moved along the horizontal axis with a random speed and direction. If the ball left the circle, the circle's color changed from blue to red. Ball movement was controlled using a gamepad. Performance feedback was provided (duration within the circle/duration of the block $* 100$ ) at the end of each block. Stimuli appeared on a 17-in. LCD monitor with a $60-\mathrm{Hz}$ refresh rate.

ERPs in response to windmill patterns were recorded. As Fig. 6 shows, the patterns consisted of either six or 12 vanes (V6 and V12). The patterns had a high contrast $\left(37.2 \mathrm{~cd} / \mathrm{m}^{2}\right.$ for the bright segments, $0.1 \mathrm{~cd} / \mathrm{m}^{2}$ for the dark ones). The diameter of the pattern was $13.82^{\circ}$, and the background was gray $\left(16.0 \mathrm{~cd} / \mathrm{m}^{2}\right)$.

There were two conditions: oddball and adaptation. In the oddball condition, the stimulus duration was $100 \mathrm{~ms}$ and the ISI was $400 \mathrm{~ms}$. Both the V6 and V12 stimuli served as deviants. As in Experiment 1, both homogeneous (test stimulus identical to the standard/adaptor) and heterogeneous (test stimulus differed from the standard/adaptor) sequences were presented. The adaptation condition was identical to the filled condition in Experiment 1. The duration of the test stimulus was $100 \mathrm{~ms}$, and that of the adaptor stimulus was 1,100-3,100 ms (mean = $2,100 \mathrm{~ms}$ ). The interval between the offset of the adaptor and the onset of the short stimulus was $400 \mathrm{~ms}$. The experimental session consisted of eight sequences: four oddball sequences and 
ODDBALL
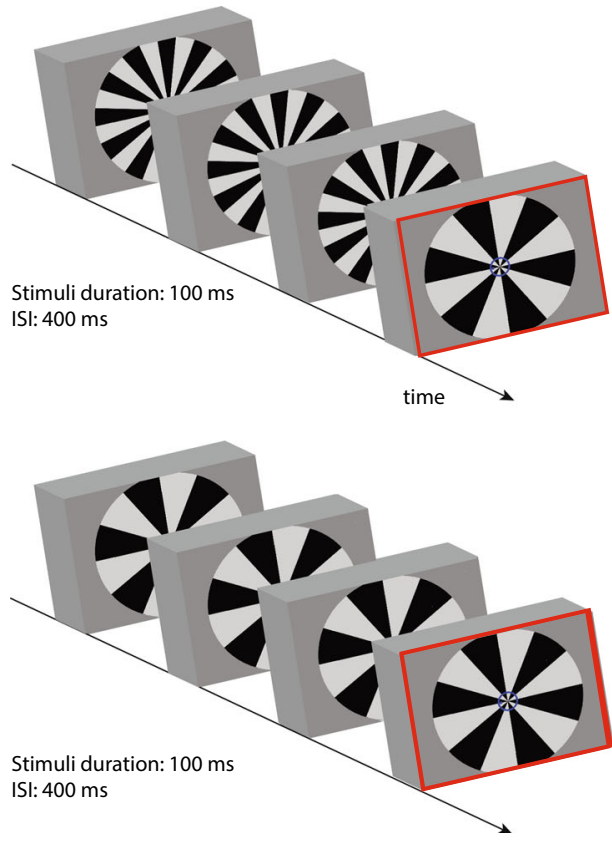

HOMOGENEOUS CONTROL
ADAPTATION
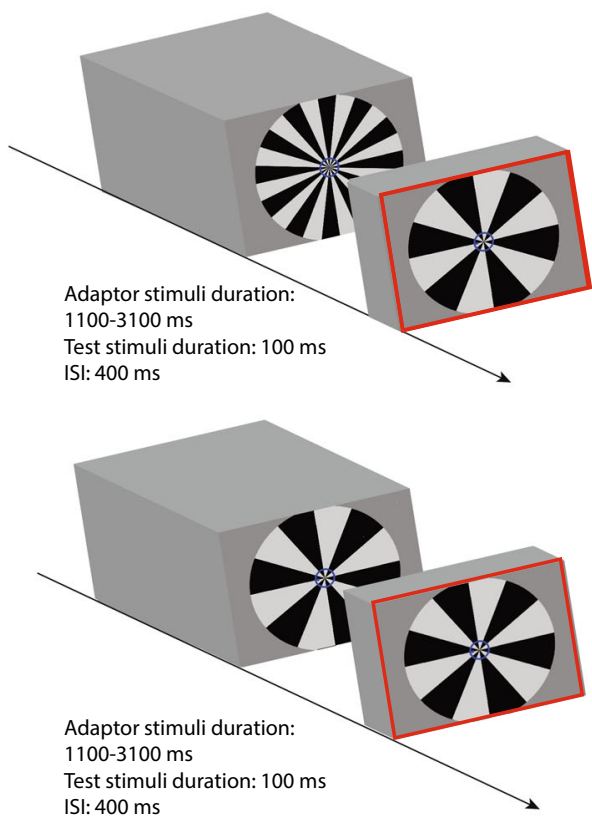

HOMOGENEOUS CONTROL

Fig. 6 Experiment 2: Outline of the stimuli and stimulus sequences in the oddball and adaptation conditions. The color frames (not present in the real stimuli) indicate the stimuli that elicited the event-related potentials used for comparison

four adaptation sequences (Homogeneous/Heterogeneous Sequences $\times$ Reverse Control Sequences). The oddball condition consisted of 800 stimuli (136 were deviant; $p=.13$ ). The filled condition consisted of 272 stimuli with 144 short stimuli. The average sequence duration was $4.9 \mathrm{~min}$. The stimuli and an outline of the experimental design are shown in Fig. 6.

Measurement of electrical brain activity The procedures for EEG registration, ERP acquisition and measurement, and data processing were identical to those in Experiment 1. In Experiment 2, difference potentials were measured at two latencies. According to the series of $t$ tests on the deviantminus-standard difference potentials, the $t$ values in the oddball condition were significant within a long range (90-228 ms). Following Kimura et al. (2009) and Maekawa et al. (2009), we divided this range into two time windows, and the difference was characterized within a 20-ms epoch centered on the peak negative value within each time window. Due to the large ERP differences between the V6 and V12 stimuli, we report these differences in terms of a complexity factor.

\section{Results}

Behavioral results Performance accuracy was $98.8 \%$ and 98.0\% during the oddball and adaptation tasks, respectively.
According to a two-way ANOVA with the factors Task and Deviancy (V6 vs. V12), there were no performance differences.

Event-related potentials Figure 7 shows the event-related potentials and the deviant-minus-standard difference potentials in the two (oddball and adaptation) conditions. As in Experiment 1, only the condition-related effects are reported.

Exogenous components to the centrally presented windmill patterns were markedly different from those elicited be the texture of the oblique lines in Experiment 1. A positivity at a mean latency of 100-110 ms (P1) was followed by a wide negativity (N1) in the 140 - to $200-\mathrm{ms}$ range. This negativity did not reach the baseline on the majority of trials. Following the N1, a second positivity (P2) emerged within the 200- to 300 -ms range. Table 3 shows the latencies and amplitudes of the exogenous components $(\mathrm{P} 1, \mathrm{~N} 1, \mathrm{P} 2)$ at the two ROIs.

Difference potentials With the exception of the potentials at the occipital ROI in response to the V6 stimuli of the oddball task, the negative difference potentials differed significantly from zero $[t(17)=1.76-9.77$; for significant effects, the alpha levels were at least .05, Bonferroni-corrected] during the earlier latency period (118-138 ms).

The differences between the two conditions during the earlier latency period were analyzed using a three-way 


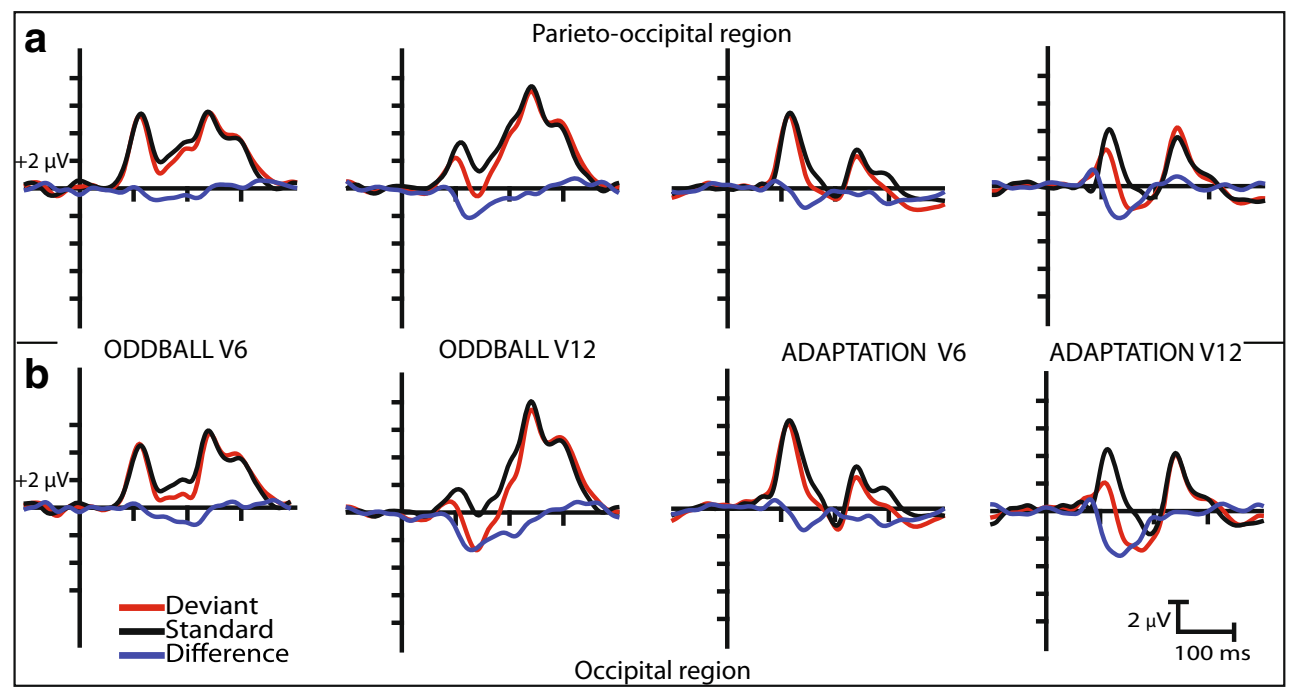

Fig. 7 Experiment 2: Event-related potentials and difference potentials in the oddball and adaptation conditions at the parieto-occipital and occipital regions of interest

ANOVA with Complexity (V6, V12), Condition (oddball, adaptation), and ROI as factors.

Neither the latency nor the amplitude of the negativity differed between the oddball and adaptation conditions (no main effect of condition). For the amplitude values, the main effect of complexity $\left[F(1,18)=40.10, p<.001, \eta_{\mathrm{p}}{ }^{2}=.69\right]$ and the Condition $\times$ ROI interaction $\left[F(1,18)=4.78, p<.05, \eta_{\mathrm{p}}^{2}=\right.$ .21] were significant.

During the later latency period (198-218 ms), the significant Bonferroni-corrected $t$ tests only appeared at the occipital
ROI in the oddball condition $[t(17)=4.01$ and 3.34 at $\mathrm{V} 12$ and V6, respectively; $p<.05]$ and at the parieto-occipital ROI with V12 stimuli in the oddball condition $[t(17)=2.12, p<.05]$. Table 4 shows the latencies and amplitudes of the difference potentials. Figure 8 shows the difference potentials and their surface distributions within the ranges of the negativities.

The effect of onset-to-onset time Figure 9 shows the ERPs in response to the deviant stimuli of the oddball and adaptation conditions, as well as the differences between them. As the

Table 3 Experiment 2: Grand averages of the epoch mean amplitudes and peak latencies of the exogenous components (P1, N1, P2) measured at the parieto-occipital and occipital regions

\begin{tabular}{llllllll}
\hline & & & & & P1 & \\
\hline Region & Stimulus & Amplitude $(\mu \mathrm{V})$ & Latency $(\mathrm{ms})$ & Amplitude $(\mu \mathrm{V})$ & Latency $(\mathrm{ms})$ & Amplitude $(\mu \mathrm{V})$ & Latency $(\mathrm{ms})$ \\
Parieto-occipital & V6 oddball deviant & $5.09 \pm 0.61$ & $114.56 \pm 3.55$ & $1.38 \pm 0.42$ & $157.67 \pm 7.39$ & $5.46 \pm 0.93$ & $249.44 \pm 5.3$ \\
& V6 oddball standard & $5.26 \pm 0.6$ & $119.56 \pm 5$ & $2.17 \pm 0.44$ & $164.44 \pm 5.98$ & $5.58 \pm 0.73$ & $235.33 \pm 5.71$ \\
& V6 adaptation deviant & $5.02 \pm 0.54$ & $113.22 \pm 1.38$ & $-0.64 \pm 0.6$ & $190.67 \pm 7.53$ & $2.13 \pm 0.65$ & $238.22 \pm 8.57$ \\
& V6 adaptation standard & $5.19 \pm 0.5$ & $115.89 \pm 1.51$ & $-0.42 \pm 0.54$ & $194.33 \pm 3.95$ & $2.64 \pm 0.46$ & $239.11 \pm 6.19$ \\
& V12 oddball deviant & $2.07 \pm 0.59$ & $96.56 \pm 3.67$ & $-0.42 \pm 0.64$ & $145.89 \pm 5.14$ & $7.05 \pm 0.9$ & $242.78 \pm 5.6$ \\
& V12 oddball standard & $3.17 \pm 0.62$ & $112 \pm 6.78$ & $1.46 \pm 0.6$ & $140.44 \pm 6.31$ & $7.37 \pm 0.76$ & $237.22 \pm 4.19$ \\
& V12 adaptation deviant & $2.35 \pm 0.51$ & $107 \pm 4.75$ & $-1.34 \pm 0.64$ & $168.44 \pm 5.81$ & $4.06 \pm 0.67$ & $241.22 \pm 3.88$ \\
& V12 adaptation standard & $3.7 \pm 0.59$ & $119.56 \pm 5.31$ & $-0.73 \pm 0.72$ & $179 \pm 5.27$ & $3.32 \pm 0.5$ & $244.89 \pm 4.53$ \\
Occipital & V6 oddball deviant & $4.37 \pm 0.76$ & $115.22 \pm 5.41$ & $0.8 \pm 0.73$ & $162.44 \pm 9.26$ & $5.17 \pm 1.06$ & $248.11 \pm 5.21$ \\
& V6 oddball standard & $4.3 \pm 0.7$ & $122.78 \pm 6.06$ & $1.4 \pm 0.71$ & $173.33 \pm 6.67$ & $5.48 \pm 0.84$ & $241.67 \pm 5.28$ \\
& V6 adaptation deviant & $5.8 \pm 0.63$ & $112 \pm 1.45$ & $-1.3 \pm 0.67$ & $205.33 \pm 5.35$ & $1.96 \pm 0.68$ & $243.67 \pm 4.47$ \\
& V6 adaptation standard & $6.08 \pm 0.64$ & $114.44 \pm 2.04$ & $-0.97 \pm 0.6$ & $198.78 \pm 3.62$ & $2.83 \pm 0.42$ & $241.89 \pm 4.4$ \\
& V12 oddball deviant & $0.26 \pm 0.69$ & $91.78 \pm 6.12$ & $-2.62 \pm 0.94$ & $145.22 \pm 5.32$ & $7.23 \pm 1.11$ & $243.44 \pm 5.7$ \\
& V12 oddball standard & $1.49 \pm 0.82$ & $110.67 \pm 8.62$ & $0.03 \pm 0.73$ & $132.44 \pm 6.33$ & $7.84 \pm 1.03$ & $237.11 \pm 4.98$ \\
& V12 adaptation deviant & $1.74 \pm 0.64$ & $104.11 \pm 5.84$ & $-2.72 \pm 0.83$ & $172.22 \pm 5.54$ & $3.78 \pm 0.88$ & $248.33 \pm 5.47$ \\
& V12 adaptation standard & $4.04 \pm 0.67$ & $117.89 \pm 4.49$ & $-1.51 \pm 0.74$ & $184.78 \pm 7.03$ & $3.83 \pm 0.54$ & $243.56 \pm 4.57$ \\
& & & & & &
\end{tabular}

Values represent the means \pm standard errors 
Table 4 Experiment 2: Grand averages of the epoch mean amplitudes and peak latencies of the difference waves measured at different regions (parieto-occipital and occipital)

\begin{tabular}{llllll}
\hline & & $118-138 \mathrm{~ms}$ & & \multicolumn{2}{c}{$198-218 \mathrm{~ms}$} \\
\hline Region & Stimulus & Amplitude $(\mu \mathrm{V})$ & Latency $(\mathrm{ms})$ & Amplitude $(\mu \mathrm{V})$ & Latency $(\mathrm{ms})$ \\
Parieto-occipital & V6 oddball difference & $-0.67 \pm 0.22$ & $139.67 \pm 6.08$ & $-0.61 \pm 0.35$ & $206.11 \pm 4.36$ \\
& V6 adaptation difference & $-0.83 \pm 0.3$ & $141.22 \pm 3.04$ & $-0.27 \pm 0.41$ & $204.78 \pm 7.63$ \\
& V12 oddball difference & $-2.1 \pm 0.25$ & $126.44 \pm 3.34$ & $-0.78 \pm 0.35$ & $198 \pm 7.61$ \\
& V12 adaptation difference & $-2.19 \pm 0.29$ & $132.56 \pm 3.6$ & $0.16 \pm 0.39$ & $190.89 \pm 9.5$ \\
Occipital & V6 oddball difference & $-0.42 \pm 0.25$ & $138.89 \pm 6.93$ & $-1.21 \pm 0.31$ & $207.11 \pm 3.66$ \\
& V6 adaptation difference & $-1.02 \pm 0.27$ & $141 \pm 3.6$ & $-0.47 \pm 0.39$ & $213.22 \pm 5.72$ \\
& V12 oddball difference & $-2.75 \pm 0.43$ & $129.56 \pm 3.31$ & $-1.73 \pm 0.51$ & $203.22 \pm 6.04$ \\
& V12 adaptation difference & $-3.06 \pm 0.33$ & $128.22 \pm 3.94$ & $-0.52 \pm 0.35$ & $199.22 \pm 7.98$ \\
\hline
\end{tabular}

Values represent the means \pm standard errors

figure shows, for both the V6 and V12 patterns the ERPs were more negative in the adaptation condition. The difference remained significant over a long period of time (154-400 ms for V6 and 160-380 ms for V12).

N1 and deviancy In Experiment 2, the stimuli elicited a small N1-like negativity at a much later latency than the difference potential. Therefore, in this experiment it was unnecessary to compare the exogenous negativities to the difference potentials.

\section{Discussion}

The oddball condition of Experiment 2 replicated and extended the findings reported by Maekawa et al. (2005; Maekawa et al., 2013; Maekawa et al., 2009), in a design that demanded continuous fixation to the task-related events. We obtained deviant-minus-standard differences during an early and a late latency period. As for the comparison between the oddball and adaptation conditions, during the early latency period the latencies and amplitudes of the negativities were similar. Therefore, within this latency period the negativity was

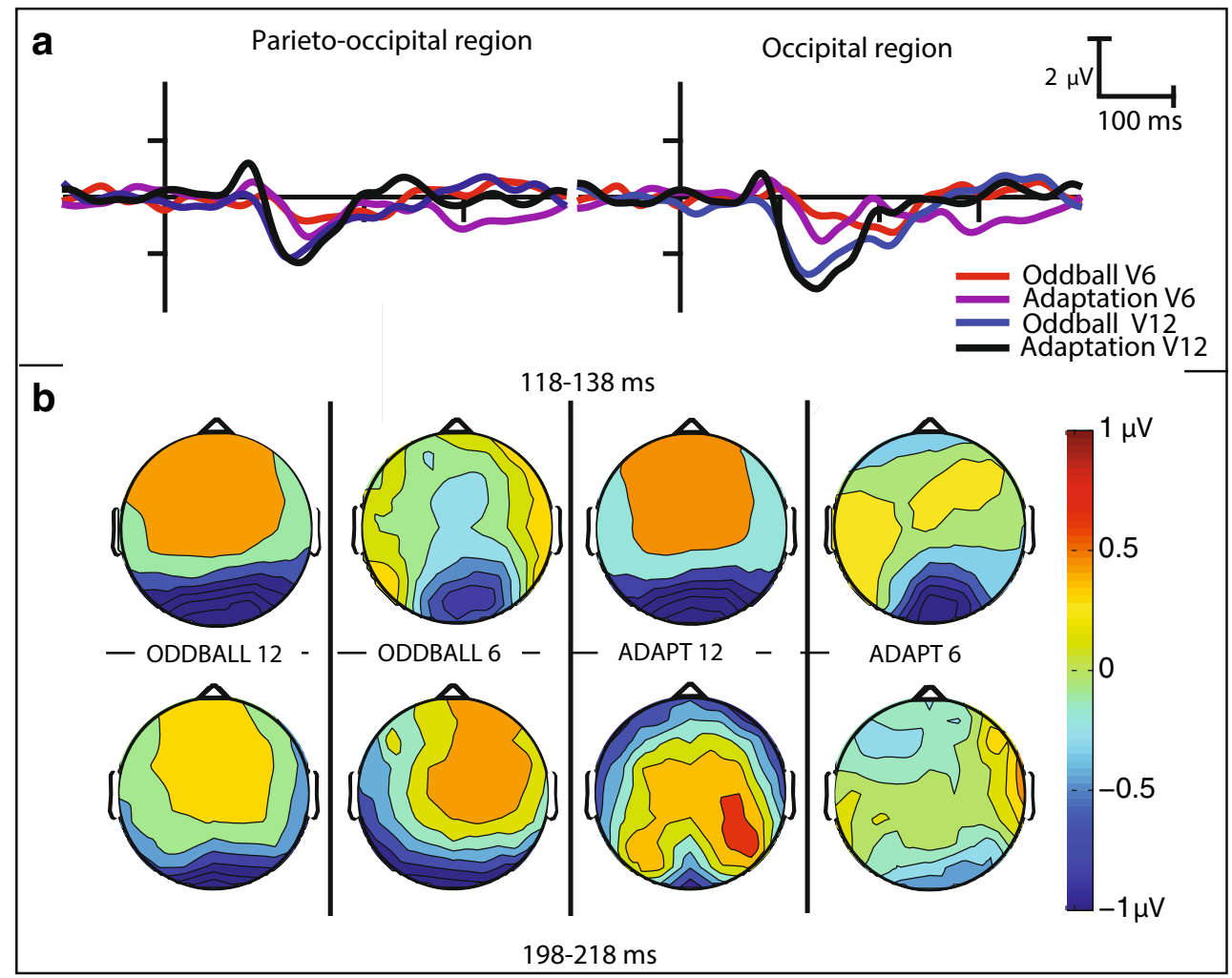

Fig. 8 Experiment 2: Difference potentials from the oddball and adaptation conditions, as well as the surface distributions of those difference potentials 


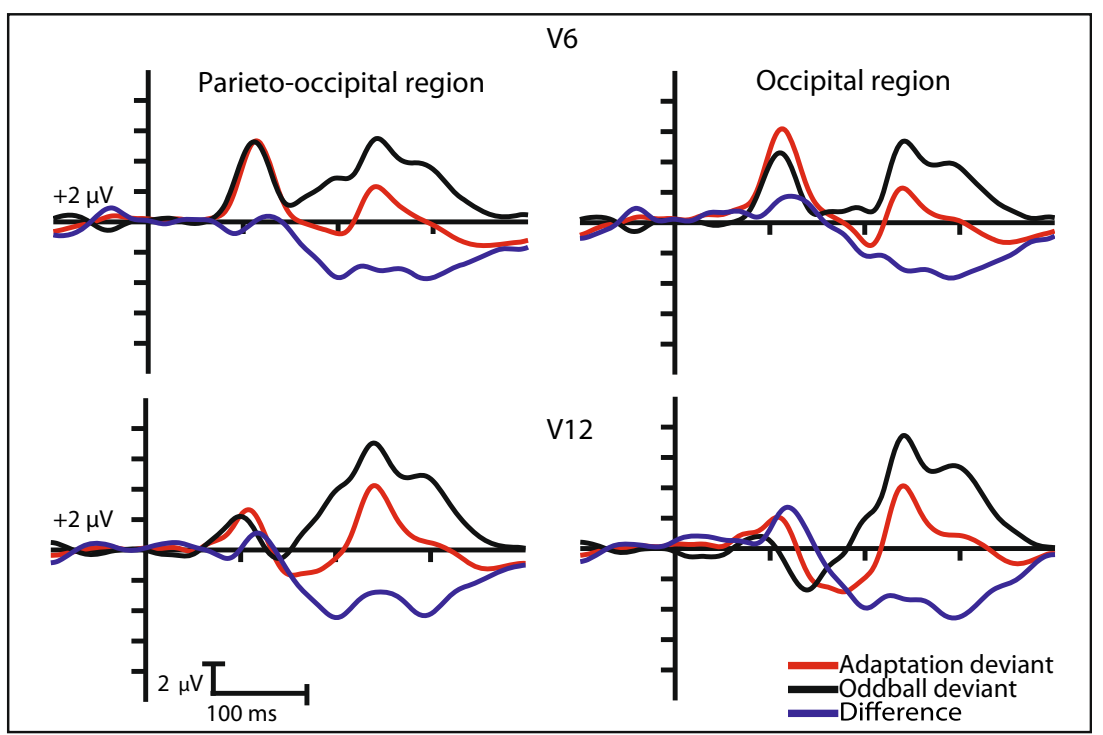

Fig. 9 Experiment 2: Event-related potentials and difference potentials from the heterogenous sequences of the oddball and adaptation conditions

unrelated to violations of a sequential rule and can be considered as SSA effect. The negativity cannot be considered a modulation of the $\mathrm{N} 1$ component because the latency of the small N1 was outside of the latency period of the deviantrelated negativity.

In the later latency period we did not find a significant negativity in the adaptation condition; however, deviant-related negativity emerged in the oddball condition. Negativities within this time period are considered to reflect violations of sequential regularity. The results of Experiment 2 correspond to the suggestion proposed by Kimura et al. (2009) - that is, whereas the early difference potential is a consequence of adaptation processes, the appearance of the genuine vMMN is restricted to a later time window.

Apart from the condition-related effects, deviant stimuli of the oddball and adaptation conditions elicited markedly different ERPs. This difference emerged as a long-lasting negativity in the adaptation deviant minus oddball deviant difference potentials. As these effects indicate, the event-related activities elicited by onset-to-onset durations differ from those elicited by stimulus changes.

\section{General discussion}

We compared deviance-related ERP effects during the oddball and adaptation conditions. Both paradigms were passive. The participants performed either a computer game or a tracking task unrelated to the ERP-related stimuli. Task performance was different in the two experiments, but more importantly, both tasks demanded continuous fixation. Furthermore, as Kimura and Takeda (2013) pointed out, task difficulty does not affect vMMN amplitudes, but in the case of a more difficult task the vMMN latency becomes slightly longer. In both paradigms we investigated the effects of stimulus changes. During the oddball conditions, we examined the difference between ERPs in response to rare (deviant) and frequent (standard) stimuli. During the adaptation conditions, we examined differences between the ERPs elicited by stimuli that differed from the adaptor (deviant) and those that were identical to the adaptor (standard). Two types of stimuli were introduced: textures of oblique lines (Exp. 1) and windmill patterns (Exp. 2). As a general finding, the ERPs in response to deviant stimuli were more negative than the ERPs in response to the standard over the posterior region. In Experiment 1, when the orientation of the lines within a texture differed from the orientation in the standard, the negativity emerged at a mean latency of $122 \mathrm{~ms}$. In Experiment 2, in which the vanes of the windmill patterns differed from the standard, the negativity in response to the deviant in the early period (with 128ms mean latency) was larger. In the oddball condition the negativity extended to a later window (208-ms mean latency). The similarities between the posterior negativities in Experiment 1 and those emerging in the early period in Experiment 2 on both oddball and adaptation trials can be adequately explained by stimulus-specific adaptation (SSA).

The difference between the deviancy effects from the stimuli in Experiment 1 (line texture) and Experiment 2 (windmill pattern) are obvious, but these findings are not consistent with the previous results (Sulykos \& Czigler, 2011; Maekawa et al., 2005; Maekawa et al., 2013; Maekawa et al., 2009). To explain this difference, we can only speculate. Orientation deviancy was presented as a line texture, whereas the windmill pattern was presented as an object. In the visual world, textures usually belong to the background and objects belong to the foreground. Assuming that objects are more important stimuli, it is possible that they are more efficient in establishing memory representations and signaling mismatch. The 
results from vMMN studies on orientation deviancy support this possibility. In a study by Kimura et al. (2009), the stimuli were objects (single bars). A deviant minus standard longlasting negativity appeared; however, the early component was eliminated by the equal-probability control (a "genuine" vMMN within the 180 - to 300 -ms range). In another study using single bars, the peak latency of the vMMN was $\sim 190 \mathrm{~ms}$ (Astikainen \& Hietanen, 2009). Kimura and Takeda (2013) presented a pattern of lines around the task field. These lines were arranged in a rectangular frame forming an object (a fairly good "Gestalt"). The time range of the "genuine" vMMN was 150-300 ms. Finally, Takács et al. (2013) presented elongated Gábor patches in two concentric circles (i.e., object-related stimuli) around the task field and reported deviant-minus-standard differences in two successive ranges within the 120- to 240-ms time windows in Experiment 1. In Experiment 2 the peak latencies occurred within the 136- to 162-ms window; however, the negativities terminated well beyond $200 \mathrm{~ms}$. Undoubtedly, direct experimentation will be required in order to address this possibility.

SSA is usually considered a decrease in the activity of particular ERP components. Specifically, in oddball studies the decrement of activity observed with the presentation of standard stimuli is generally connected to a reduced N1 amplitude (e.g., May \& Tiitinen, 2010, for the auditory, and Kimura et al., 2009, for the visual, modality). The duration of the $\mathrm{N} 1$ was longer than the negative deflection within the difference potentials, and the peak latency of the N1 was longer. However, during vision tasks, the posterior $\mathrm{N} 1$ peaks consist of a set of subcomponents (e.g., Di Russo et al., 2002; Di Russo et al., 2005); therefore, it is possible that several subcomponents are prone to stimulusspecific adaptation and that others are not. The adapted N1 explanation does not fit the results of Experiment 2. In these conditions, the $\mathrm{N} 1$ was rather small and the difference potentials were outside the $\mathrm{N} 1$ range. If we maintain the adaptation explanation, an obvious question arises: "What is adapting?" The latency range of the deviant-minus-standard difference potential, and the source analysis of the exogenous activities within this range indicate that these activities originated from brain areas beyond the primary input structures of visual cortex (e.g., Di Russo et al., 2002). Furthermore, in this range the eventrelated activity is influenced by factors other than the physical characteristics of the visual events and spatial attention effects. These factors involve the intention to discriminate (e.g., Hopf, Vogel, Woodman, Heinze, \& Luck, 2002) and other task-related effects (Zani et al., 2015). Such studies have demonstrated the effects of different forms of attention - in other words, top-down influences. Nonattentional factors, such as prior exposure and probability-related effects, may also influence the activity of various visual structures within this range in a proactive manner. In fact, anterior priming effects have been shown at $\sim 150 \mathrm{~ms}$ (Schendan \& Kutas, 2003; Voss, Schendan, \& Paller, 2010). Furthermore, in some vMMN studies anterior activity has emerged in the range of the posterior negativity (e.g., Heslenfeld, 2003; Kimura, Kondo, Ohira, \& Schröger, 2012; Kimura, Ohira, \& Schröger, 2010; Urakawa, Inui, Yamashiro, $\&$ Kakigi, 2010). We suggest that the SSA-related negativity is a consequence of the activity of a broader neural network, and the latency of this network's activity can differ from that of other exogenous ERP components.

In contrast to the traditional view (Kimura, 2012; Stefanics et al., 2011; Winkler \& Czigler, 2012), we suggest that in vision, the memory-related deviant-minus-standard ERP difference does not always require sequential stimulation. To our knowledge, a similar possibility has not been explored in the auditory modality. In the oddball condition of Experiment 2, a significant negativity during the later latency period emerged only in the oddball condition. Therefore, this negativity can be considered a genuine vMMN. Using an equal-probability control (Jacobsen \& Schröger, 2001; Schröger \& Wolff, 1998), genuine vMMNs with similar latencies have appeared in response to orientation deviancy (Kimura et al., 2009) and complex stimulus characteristics, such as facial emotions (Li et al., 2012). Accordingly, we suggest that the later negativity of Experiment 2 is connected to the violation of sequential rules.

In addition to the negativity in the deviant-minus-standard difference potentials, the effects of onset-to-onset duration also appeared in both experiments. In Experiment 1 a long-lasting negative potential difference emerged as a function of the duration between the two deviant stimuli (i.e., larger negativity in the filled-minus-oddball than in the squeezed-minus-oddball difference). This effect began within the range of the N1 component. In Experiment 2 we observed a negative shift in the adaptation-minus-oddball difference potentials. This shift was more pronounced in the later (P2) period. SOA and/or ISI effects on the ERP responses to auditory stimuli are well known, but such effects have been less investigated in vision. However, as a long-lasting negativity, this difference cannot be attributed to changes in a particular ERP component. It is an open question whether filled periods (as in the present study) are needed for the emergence of such a negativity, or whether the effect would be the same with empty interstimulus fields.

\section{Conclusions}

During the oddball and adaptation conditions in two experiments with two sets of stimuli (textures of oblique lines and windmill patterns), the posterior negativity ERP differences in response to standard and deviant stimuli were similar in the 100- to $140-\mathrm{ms}$ time window. This results suggests that in vision, the acquisition of sequential regularities is unnecessary for eliciting posterior negativities in this early latency period. As our results with the windmill patterns show, in a later latency period the negativity in the oddball sequence seems to be connected to the violation of sequential regularities. 
Author note This study was supported by the Hungarian Research Fund (Grant No. OTKA 104462). We thank Szonya Durant for help in polishing our English style, and Zsuzsa d'Albini and Zsuzsa Kovács for their technical help.

\section{References}

Andrade, G. N., Butler, J. S., Mercier, M. R., Molholm, S., \& Foxe, J. J. (2015). Spatio-temporal dynamics of adaptation in the human visual system: A high-density electrical mapping study. European Journal of Neuroscience, 41, 925-939.

Astikainen, P., \& Hietanen, J. K. (2009). Event-related potentials to taskirrelevant changes in facial expressions. Behavioral and Brain Functions, 5, 30. doi:10.1186/1744-9081-5-30.

Astikainen, P., Lillstrang, E., \& Ruusuvirta, T. (2008). Visual mismatch negativity for changes in orientation-A sensory memorydependent response. European Journal of Neuroscience, 28, 2319-2324.

Athanasopoulos, P., Dering, B., Wiggett, A., Kuipers, J. R., \& Thierry, G. (2010). Perceptual shift in bilingualism: Brain potentials reveal plasticity in pre-attentive colour perception. Cognition, 116, 437-443. doi:10.1016/j.cognition.2010.05.016.

Clifford, A., Holmes, A., Davies, I. R. L., \& Franklin, A. (2008). Eventrelated potentials during preattentional processing of color stimuli. Biological Psychology, 85, 275-282.

Czigler, I. (2007). Visual mismatch negativity-Violation of nonattended environmental regularities. Journal of Psychophysiology, 21, 224-230.

Czigler, I., Balazs, L., \& Winkler, I. (2002). Memory-based detection of task-irrelevant visual changes. Psychophysiology, 39, 869-873.

Czigler, I., \& Csibra, G. (1992). Event-related potentials and the identification of deviant visual stimuli. Psychophysiology, 29, 471-484

Di Russo, F., Martínez, A., Sereno, M. I., Pitzalis, S., \& Hillyard, S. A. (2002). Cortical sources of the early components of the visual evoked potential. Human Brain Mapping, 15, 95-111.

Di Russo, F., Pitzalis, S., Spitoni, G., Aprile, T., Patria, F., Spinelli, D., \& Hillyard, S. A. (2005). Identification of the neural sources of the pattern-reversal VEP. NeuroImage, 24, 874-886. doi:10.1016/j. neuroimage.2004.09.029.

Duncan, J. (1984). Selective attention and the organization of visual information. Journal of Experimental Psychology: General, 113, 501517. doi:10.1037/0096-3445.113.4.501.

File, D., Bodnár, F., Sulykos, I., Kecskés-Kovács, K., \& Czigler, I. (2017). Automatic change detection in vision: adaptation, memory mismatch, or both. II: Oddball and equivalent probability control. Manuscript submitted for publication.

Garrido, M. I., Kilner, J. M., Stephan, K. E., Klaas, E., \& Friston, K. (2008). The mismatch negativity: A review of underlying mechanisms. Clinical Neurophysiology, 120, 453-463.

Heslenfeld, D. J. (2003). Visual mismatch negativity. In J. Polich (Ed.), Detection of change: Event-related potential and fMRI findings (pp. 41-59). Boston: Kluwer Academic Press.

Hillyard, S. A., \& Münte, T. F. (1984). Selective attention to color and location: An analysis with event-related brain potentials. Perception \& Psychophysics, 36, 185-198. doi:10.3758/BF03202679.

Hopf, J.-M., Vogel, E., Woodman, G., Heinze, H.-J., \& Luck, S. J. (2002). Localizing visual discrimination processes in time and space. Journal of Neurophysiology, 88, 2088-2095.

Huang, J., Zhou, R., \& Hu, S. (2013). Effects on automatic attention due to exposure to pictures of emotional faces while performing Chinese word judgment tasks. PLoS ONE, 8, e75386. doi:10.1371/journal. pone. 0075386 .
Jacobsen, T., \& Schroger, E. (2001). Is there pre-attentive memory-based comparison of pitch? Psychophysiology, 38, 723-727.

Kanai, R., Tsuchiya, N., \& Verstraten, F. A. J. (2006). The scope and limits of top-down attention in unconscious visual processing. Current Biology, 16, 2332-2336.

Kecskés-Kovács, K., Sulykos, I., \& Czigler, I. (2013a). Is it a face of a woman or a man? Visual mismatch negativity is sensitive to gender category. Frontiers in Human Neuroscience, 7, 532. doi:10.3389/ fnhum.2013.00532.

Kecskés-Kovács, K., Sulykos, I., \& Czigler, I. (2013b). Visual mismatch negativity is sensitive to symmetry as a perceptual category. European Journal of Neuroscience, 37, 662-667. doi:10.1111/ejn.12061.

Kenemans, J. L., Hebly, W., van den Heuvel, E. H. M., \& Grent-'T-Jong, T. (2010). Moderate alcohol disrupts a mechanism for detection of rare events in human visual cortex. Journal of Psychopharmacology, 24, 839-845. doi:10.1177/0269881108098868.

Kimura, M. (2012). Visual mismatch negativity and unintentional temporal-context-based prediction in vision. International Journal of Psychophysiology, 83, 144-155.

Kimura, M., Katayama, J., Ohira, H., \& Schröger, E. (2009). Visual mismatch negativity: New evidence from the equiprobable paradigm. Psychophysiology, 46, 402-409.

Kimura, M., Kondo, H., Ohira, H., \& Schröger, E. (2012). Unintentional temporal context-based prediction of emotional faces: An electrophysiological study. Cerebral Cortex, 22, 1774-1785. doi:10.1093/ cercor/bhr244.

Kimura, M., Ohira, H., \& Schröger, E. (2010). Localizing sensory and cognitive systems for pre-attentive visual deviance detection: An sLORETA analysis of the data of Kimura et al. (2009). Neuroscience Letters, 485, 198-203. doi:10.1016/j.neulet.2010.09.011.

Kimura, M., Schröger, E., Czigler, I. (2011). Visual mismatch negativity and its importance in visual cognitive sciences. Neuroreport 22(14): 669-73. doi:10.1097/WNR.0b013e32834973ba.

Kimura, M., \& Takeda, J. (2013). Task difficulty affects the predictive process indexed by visual mismatch negativity. Frontiers in Human Neuroscience, 7, 261. doi:10.3389/fnhum.2013.00261.

Kimura, M., Widmann, A., \& Schröger, E. (2010). Top-down attention affects sequential regularity representation in the human visual system. International Journal of Psychophysiology, 77, 126-134. doi: 10.1016/j.ijpsycho.2010.05.003

Kohn, A. (2007). Visual adaptation: Physiology, mechanism and functional benefits. Journal of Neurophysiology, 97, 3155-3164.

Kovács, G., Cziraki, C., Vidnyánszky, Z., Schweinberger, S. R., \& Greenlee, M. W. (2008). Position-specific and position-invariant face aftereffects reflect the adaptation of different cortical areas. NeuroImage, 43, 156-164. doi:10.1016/j.neuroimage.2008.06.042.

Kreegipuu, K., Kuldkepp, N., Sibolt, O., Toom, M., Allik, J., \& Näätänen, R. (2013). vMMN for schematic faces: Automatic detection of change in emotional expression. Frontiers in Human Neuroscience, 7, 714. doi:10.3389/fnhum.2013.00714

Kremláček, J., Kreegipuu, K., Tales, A., Astikainen, P, Põldver, N., Näätänen, R., \& Stefanics, G. (2016). Visual mismatch negativity (vMMN): A review and meta-analysis of studies in psychiatric and neurological disorders. Cortex, 80, 76-112.

Kremláček, J., Kuba, M., Kubov, A. Z., Langrov, A. J., Kubova, Z., \& Langrova, J. (2006). Visual mismatch negativity elicited by magnocellular system activation. Vision Research, 46, 485-490.

Larsson, J., \& Harrison, S. J. (2015). Spatial specificity and inheritance of adaptation in human visual cortex. Journal of Neurophysiology, 114, 1211-1226.

Lehtonen, J. B. (1973). Functional differentiation between late components of visual evoked potentials recorded at occiput and vertex: Effect of stimulus interval and contour. Electroencephalography and Clinical Neurophysiology, 35, 75-82. 
Li X., Lu Y., Sun G., Gao L., Zhao L. (2012). Visual mismatch negativity elicited by facial expressions: new evidence from the equiprobable paradigm. Behav. Brain Func, 8, 7 doi:10.1186/1744-9081-8-7

Liu, T., \& Shi, J. (2008). Event-related potentials during preattentional processing of color stimuli. Neuroreport, 19, 1221-1225.

Luck, S. J. (2005). An introduction to the event-related potential technique. Cambridge: MIT Press.

Maekawa, T., Goto, Y., Kinukawa, N., Taniwaki, T., Kanba, S., \& Tobimatsu, S. (2005). Functional characterization of mismatch negativity to a visual stimulus. Clinical Neurophysiology, 116, 2392-2402.

Maekawa, T., Katsuki, S., Kishimoto, J.,Onitsuka, T., Ogata, K., Yamasaki, T., .. \& Kanba, S. (2013). Altered visual information processing systems in bipolar disorder: Evidence from visual MMN and P3. Frontiers in Human Neuroscience, 7, 403. doi:10.3389/ fnhum.2013.00403

Maekawa, T., Tobimatsu, S., Ogata, K., Onitsuka, T., \& Kanba, S. (2009). Preattentive visual change detection as reflected by the mismatch negativity (MMN)-Evidence for memory-based process. Neuroscience Research, 65, 107-112.

May, P., \& Tiitinen, H. (2010). Mismatch negativity (MMN), the devianceelicited auditory deflection explained. Psychophysiology, 47, 66-122.

Mo, L., Xu, G., Kay, P., \& Tan, L. H. (2011). Electrophysiological evidence for the left-lateralized effect of language on preattentive categorical perception of color. Proceedings of the National Academy of Sciences, 108, 14026-14030. doi:10.1073/pnas.1111860108

Müller, D., Roeber, U., Winkler, I., Trujillo-Barreto, N., Czigler, I., \& Schröger, E. (2012). Impact of lower- vs. upper-hemifield presentation on automatic colour-deviance detection: A visual mismatch negativity study. Brain Research, 1472, 89-98. doi:10.1016/j. brainres.2012.07.016

Näätänen, R., Jacobsen, T., \& Winkler, I. (2005). Memory-based or afferent processes in mismatch negativity (MMN): A review of the evidence. Psychophysiology, 42, 25-32.

Näätänen, R., Paavilainen, P., Rinne, T., \& Alho, K. (2007). The mismatch negativity (MMN) in basic research of central auditory processing: A review. Clinical Neurophysiology, 118, 2544-2590. doi: 10.1016/j.clinph.2007.04.026

Neville, H. J., Schmidt, A., \& Kutas, M. (1983). Altered visual-evoked potentials in congenitally deaf adults. Brain Research, 266, 127-132.

O'Shea, R. P. (2015). Refractoriness about adaptation. Frontiers in Human Neuroscience, 9, 38. doi:10.3389/fnhum.2015.00038

Park, S., Intraub, H., Yi, D.-J., Widders, D., \& Chun, M. (2007). Beyond the edges of a view: Boundary extension in human scene-selective visual cortex. Neuron, 54, 335-342.

Pazo-Alvarez, P., Amenedo, E., \& Cadaveira, F. (2004). Automatic detection of motion direction changes in the human brain. European Journal of Neuroscience, 19, 1978-1986.

Pereira, D. R., Cardoso, S., Ferreira-Santos, F., Fernandes, C., CunhaReis, C., Paiva, T. O., ... \& Marques-Teixeira, J. (2014). Effects of inter-stimulus interval (ISI) duration on the $\mathrm{N} 1$ and $\mathrm{P} 2$ components of the auditory event-related potential. International Journal of Psychophysiology, 94, 311-318.

Schendan, H. E., \& Kutas, M. (2003). Time course of processes and representation supporting visual object identification and memory. Journal of Cognitive Neuroscience, 15, 111-135.
Schröger, E., \& Wolff, C. (1996). Mismatch response of the human brain to changes in sound location. Neuroreport, 7, 3005-3008.

Schröger, E., Wolff, C. (1998).Behavioral and electrophysiological effects of task-irrelevant sound change: a new distraction paradigm. Brain Res Cogn Brain Res (1):71-87.

Stefanics, G., Csukly, G., Komlosi, S., Czobor, P., \& Czigler, I. (2012). Processing of unattended facial emotions: A visual mismatch negativity study. NeuroImage, 59, 3042-3049.

Stefanics, G., Kimura, M., \& Czigler, I. (2011). Visual mismatch negativity reveals automatic detection of sequential regularity violation. Frontiers in Human Neuroscience, 5, 46. doi:10.3389/fnhum.2012.00046

Stefanics, G., Kremláček, J., \& Czigler, I. (2014). Visual mismatch negativity: A predictive coding view. Frontiers in Human Neuroscience, 8, 666. doi:10.3389/fnhum.2014.00666

Sulykos, I., \& Czigler, I. (2011). One plus one is less than two: Visual features elicit non-additive mismatch-related brain activity. Brain Research, 1398, 64-71.

Susac, A., Heslenfeld, D. J., Huonker, R., \& Supek, S. (2014). Magnetic source localization of early visual mismatch response. Brain Topography, 27, 648-651. doi:10.1007/s10548-013-0340-8

Sysoeva, O. V., Lange, E. B., Sorokin, A. B., \& Campbell, T. (2014). From pre-attentive processes to durable representation: An ERP index of visual distraction. International Journal of Psychophysiology, 95, 310-320.

Takács, E., Sulykos, I., Czigler, I., Barkaszi, I., \& Balázs, L. (2013). Oblique effect in visual mismatch negativity. Frontiers in Human Neuroscience, 7, 591. doi:10.3389/fnhum.2013.00591

Urakawa, T., Inui, K., Yamashiro, K., \& Kakigi, R. (2010). Cortical dynamics of the visual change detection process. Psychophysiology, 47, 905-912.

Voss, J. J., Schendan, H. F., \& Paller, K. A. (2010). Finding meaning in novel geometric shapes influences electrophysiological correlates of repetition and dissociates perceptual and conceptual priming. NeuroImage, 49, 2879-2889.

Wastell, D. G., \& Kleinman, D. (1980). Fast habituation of the late components of the visual evoked potential in man. Physiology and Behavior, 25, 93-97.

Webster, M. A. (2011). Adaptation and visual coding. Journal of Vision, 11(5), 1-23. doi:10.1167/11.5.3

Wijers, A. A., Mulder, G., Okita, T., \& Mulder, L. J. M. (1989). Eventrelated potentials during memory search and selective attention to letter size and conjunction of letter size and color. Psychophysiology, $26,529-547$

Winkler, I., \& Czigler, I. (2012). Evidence from auditory and visual eventrelated potential (ERP) studies of deviance detection (MMN and vMMN) linking predictive coding theories and perceptual object representations. International Journal of Psychophysiology, 82, 132-143.

Zani, A., Marsili, G., Senerchia, Annapaola, Proverbio, A.M., (2015). ERP signs of categorical and supra-categorical processing of visual information. Biological Psychology 104:90 - 107. doi:10.1016/j. biopsycho.2014.11.012

Zhao, L., \& Jing, L. (2006). Visual mismatch negativity elicited by facial expressions under non-attentional condition. Neuroscience Letters, $410,126-131$ 